\title{
OS EMPRESÁRIOS, A PÁTRIA E A BOLA: NACIONALISMO, ORGANIZAÇÃO EMPRESARIAL E O FINANCIAMENTO DA SELEÇÃO BRASILEIRA DE FUTEBOL DE 1970
}

The entrepreneurs, the homeland and the ball: nationalism, business organization and the financing of the 1970 Brazilian soccer team Los empresarios, la patria y el balón: nacionalismo, organización empresarial y financiamiento del equipo de fútbol brasileño de 1970

Luiz Guilherme BurlamaQui SOARES PORTO ROCHA ${ }^{\mathrm{I}^{*}}$

DOl: http://dx.doi.org/10.1590/S2178-14942019000300006

\footnotetext{
' Instituto Federal de Brasília (IFB), Brasília - DF, Brasil.

* Professor de história do Instituto Federal de Brasilia, doutorando em história social pela Universidade de São Paulo (USP). (luiz_burlamaqui@hotmail.com) ORCID: https://orcid.org/0000-0003-0872-2318
}

Artigo recebido em 19 de junho de 2019 e aprovado para a publicação em 8 de outubro de 2019. 


\section{RESUMO}

Este artigo visa discutir a participação de parte dos empresários brasileiros no planejamento da Seleção brasileira de futebol de 1970. Conhecida pela literatura como "Planejamento México", a preparação para esse Copa envolveu o envio de técnicos brasileiros ao exterior, a capacitação da comissão técnica e uma longa estadia no México para adaptação à altitude. Os custos do Planejamento México foram bancados por empresários brasileiros em parceria com a Confederação Brasileira de Desportos. Escorado em fontes inéditas, disponibilizadas no Instituto Moreira Salles, este artigo discute os objetivos dos empresários no financiamento dos preparativos da Seleção.

PALAVRAS-CHAVE: Instituições esportivas; Ditadura empresarial-militar; Seleção brasileira de 1970, João Havelange.

\section{ABSTRACT}

This article aims to discuss the participation of Brazilian entrepreneurs in the planning of the Brazilian Seleção of 1970. Known in the literature as Planejamento México, the Brazilian preparation for the 1970 World Cup involved the interchange of Brazilian technicians, the preparation of the technical committee and a long stay in Mexico to adapt to altitude. The costs of Planning Mexico were financed by Brazilian entrepreneurs in partnership with the Brazilian Sports Confederation. Based in unpublished sources, available at Instituto Moreira Salles, this article discusses the entrepreneurs' objectives in financing the preparations for the Seleção.

KEYwORDS: Sports institutions; Business-military dictatorship; 1970 Brazilian National Team; João Havelange.

\section{RESUMEN}

En este artículo se pretende discutir la participación de parte de los empresarios brasileños en la planificación de la selección brasileña de 1970. Conocida por la literatura como "Planejamento México", la preparación brasileña para dicho Mundial involucró el envío de técnicos brasileños al exterior, la capacitación de la comisión técnica y una larga estancia en México para adaptación a la altitud. Los costos del planejamento fueron bancados por empresarios brasileños en asociación con la Confederación Brasileña de Deportes. En este artículo se discuten los objetivos de los empresarios en la financiación de los preparativos de la Seleção.

PALABRAS ClAVE: Instituciones deportivas; Dictadura empresarial-militar; Equipo nacional brasileño de 1970, João Havelange. 
OS EMPRESÁRIOS, A PÁTRIA E A BOLA: NACIONALISMO, ORGANIZAÇÃO EMPRESARIAL E O FINANCIAMENTO DA SELEÇÃO BRASILEIRA DE FUTEBOL DE 1970

\section{INTRODUÇÃO}

$\mathrm{D}$ epois da eliminação da Seleção brasileira na Copa do Mundo de 1966, o presidente da Confederação Brasileira de Desportos (CBD), João Havelange, não parecia disposto a sair derrotado no torneio seguinte. Contando com a ajuda de profissionais da educação física ligados às escolas militares, Havelange, então, elaborou um plano técnico-científico para a melhor preparação física do selecionado.

Conhecido pela literatura como "Planejamento México", o plano envolvia o envio de profissionais da comissão técnica da CBD para o exterior, uma longa estadia de adaptação à altitude do México e a capacitação dos profissionais com cursos de formação (Soares, Salvador e Bartholo, 2004). Consoante ao espírito tecnocrático vigente, a crença que sustentava 0 plano era a de que, por meio do bom uso da ciência, do planejamento meticuloso e da organização técnica, seria possível alcançar a vitória na Copa do Mundo de 1970.

O problema começa quando os dirigentes percebem que as verbas da CBD não seriam suficientes para cobrir os custos do programa de treinos. No relatório anual de 1970 da entidade, Havelange estimou as despesas do Planejamento México em 9,5 milhões de cruzeiros novos, valores que, se fossem atualizados pela inflação, corresponderiam a cerca de 73 milhões de reais. ${ }^{1}$ Recorrer às verbas estatais poderia ser um problema, pois, com o capital político reduzido desde a derrota na Inglaterra, Havelange temia que um eventual insucesso na Copa de 1970 lhe pudesse gerar um processo administrativo, à maneira dos inquéritos policiais militares. "Se formos pedir dinheiro ao governo, de certa forma, isso nos obriga a ganhar a Copa de qualquer maneira. Se perdermos, é possível que eles queiram vir fazer um IPM na CBD", disse Havelange (As moedas..., 1970). A solução, então, foi recorrer diretamente à iniciativa privada.

Intermediado por Bellini Cunha, sócio do Fluminense e assessor jurídico do embaixador Walther Moreira Salles, Havelange procurou a União de Bancos Brasileiros (UBB) na tentativa de que a instituição financiasse diretamente o Planejamento México. Impossibilitado de arcar com os custos, Walther Salles propôs a Havelange mobilizar o empresariado brasileiro para arrecadar a soma solicitada pela CBD. Em vez de doar o valor integralmente, seria melhor fazer uma campanha do empresariado em defesa da Seleção.

Nessa reunião, tinha início a Campanha do Empresariado Pró-Copa do Mundo de 1970. Do valor total, os empresários foram os responsáveis por amealhar cerca de 1 milhão de cruzeiros novos, algo em torno de 9 milhões de reais. 0 resto da preparação teria sido custeado com as verbas próprias da CBD — arrecadação em amistosos e nos jogos eliminatórios, ne- 
gociação de direitos de transmissão do rádio, renda dos jogos no Maracanã e bonificações da Federação Internacional de Futebol (Fifa).

Escorado numa entrevista com o próprio Bellini Cunha e em documentos inéditos recém-disponibilizados pelo Instituto Moreira Salles (IMS), este artigo pretende recuperar essa história e discute os objetivos dos empresários no financiamento dos preparativos para a Seleção brasileira no México.

Nessa linha, o texto se baseia num conjunto de documentos disponíveis numa série de acervos, pesquisados no Brasil e no exterior. A maior parte da documentação citada se encontra parcialmente disponível — mediante solicitação de autorização do uso — no IMS do Rio de Janeiro, na Gávea. Trata-se de um arquivo privado do embaixador Walter Salles, ainda não disponibilizado integralmente por estar em fase de processamento de dados, catalogação e edição.

Nas vezes em que o pesquisador esteve no arquivo, a intenção demonstrada pelos funcionários da instituição era disponibilizar o material para consulta pública ao longo dos próximos anos. Ao pesquisador foi facultado o acesso ao fundo sobre a Copa do Mundo de 1970. Tal fundo é composto de doze pastas nas quais se encontram cartas entre os participantes da campanha, press releases, atas de reunião, recortes de jornal e uma listagem com as pessoas físicas e jurídicas que doaram dinheiro à campanha.

0 acervo dispõe também de um conjunto de fotografias, acessíveis mediante solicitação. Combinados, os documentos narram os bastidores da pouco conhecida campanha do empresariado pela Copa do Mundo de 1970. Além dos documentos escritos, para os fins do artigo, o pesquisador entrevistou um dos tesoureiros da campanha e assessor de Walter Moreira Salles, Bellini Cunha, em seu apartamento no Flamengo, em 2016.

\section{AS ORIGENS DA CAMPANHA}

$\mathrm{N}$ o fim de fevereiro de 1969, em reunião de conselheiros do Fluminense, Havelange se aproximou de Bellini Cunha. Assim como o futuro presidente da Fifa, Cunha era conselheiro e sócio do clube e tinha, nas suas próprias palavras, "um relacionamento muito grande com as pessoas ali". ${ }^{2}$ Desde 1961, ele trabalhava na UBB, o banco da família Moreira Salles. Por conta do convite de um ex-professor de direito da Faculdade Nacional, fizera os atos constitutivos de uma empresa em meio ao processo de expansão do banco. Essa empresa, por sua vez, acabou sendo adquirida pelo banco, e Cunha foi contratado como assessor de Walther Salles. No fim da década de 1960, Cunha prosperava como um dos assessores jurídicos de confiança do embaixador Walther Moreira Salles. Nessa época, 
OS EMPRESÁRIOS, A PÁTRIA E A BOLA: NACIONALISMO, ORGANIZAÇÃO EMPRESARIAL E O FINANCIAMENTO DA SELEÇÃO BRASILEIRA DE FUTEBOL DE 1970

ele [Havelange] me procurou porque estava precisando conversar com o Embaixador Moreira Salles, a respeito de um projeto de apoio para a seleção brasileira. Eu disse: "mas, olha, você tem contato com o Embaixador, não precisa ser por meu intermédio. É só procurar, Havelange". "Não. O Embaixador é muito ocupado, eu gostaria que você já preparasse ele, conversasse com ele, porque, quando eu fosse marcar, agendar com ele, ele já estivesse a par". ${ }^{3}$

A estratégia de Havelange de se aproximar de Salles se valendo de um mediador funcionou. De início, de acordo com o próprio Cunha, o embaixador estranhou a proposta:

Tive uma conversa com ele. Porque eu realmente achei que seria bom para figura dele, quer dizer ele era uma figura, vamos dizer assim, parecia que era uma pessoa que vivia numa redoma, 0 que não era, era uma pessoa muito aberta e tal. E projetar até mais, quer dizer, junto ao povo né, porque ele [já] tinha uma posição muito grande no mundo financeiro, no mundo internacional. ${ }^{4}$

Uma guinada na política financeira da UBB favorecia o investimento em marketing da seleção brasileira. Em 1970, a UBB adquiriu o Banco Predial, que tinha 108 agências espalhadas pelo Rio de Janeiro, era de caráter mais popular e ligado à comunidade portuguesa do Rio de Janeiro. Essa aquisição indicava uma mudança na política do banco. Até esse momento, a cartela da UBB se concentrava em clientes de alta renda. A compra do Banco Predial fez com que a instituição passasse a competir também entre as camadas médias e baixas da população.

Por sua força entre todas as classes sociais, a Seleção brasileira se tornou um ativo de marketing bastante valioso. Para disseminar o nome de Salles "junto ao povo", na expressão de Cunha, investir na Seleção parecia ser a estratégia adequada.

A expansão do banco ocorria à sombra do crescimento econômico da ditadura empresarial-militar. As políticas adotadas por Roberto Campos e Otávio Gouveia de Bulhões a partir de 1967 incentivavam a fusão e favoreciam a criação de conglomerados bancários, reduzindo as cartas patentes - isto é, o direito dos bancos de exercer atividade financeira junto à sociedade civil (Brandão, 2018: 285; Macarini, 2017).

Além disso, o aumento do consumo das famílias de classe média e baixa fazia com que o banco fosse atraído por esse segmento. Todavia, parece difícil associar o crescimento econômico de Salles a uma atuação política intensa pró-ditadura militar. Sua participação no regime pós-1964 é marcada por certa ambiguidade, e sua biografia foi, lamentavelmente, pouco explorada pela bibliografia. Ele não ocupou nenhum cargo público no regime político pós1964, conservando certa distância dos líderes do regime, ao contrário do que havia feito na República de 1946, quando chegou a ocupar o cargo de Ministro da Fazenda. Não obstante, a política econômica do regime militar favoreceu a concentração em várias áreas da economia, em particular o setor bancário. ${ }^{5}$ 
Em 1970, quando Havelange explicou os termos da relação e anunciou de quanto precisava, Salles concordou. Na versão de Cunha, o embaixador teria feito duas ressalvas. Primeiro, não queria envolver diretamente o nome da UBB na campanha no sentido financeiro. As doações seriam feitas do seu próprio bolso e depositadas numa conta aberta no Banco do Estado da Guanabara. 0 dono desse banco era Carlos Alberto Vieira, ele também sócio e conselheiro do Fluminense, além de amigo pessoal de Havelange. Em tempos nos quais 0 patrocínio esportivo engatinhava, havia a possibilidade de o banco de Salles ser vinculado a uma imagem de fracasso.

Nessa linha, a segunda ressalva era que não havia como disponibilizar o valor integralmente, pois se tratava de uma quantia alta. Para se ter uma ideia, o valor total solicitado era 1 milhão de cruzeiros novos, pouco mais de dez por cento do total de gastos previstos pela CBD. ${ }^{6}$ Difícil aferir quão significativo era esse valor na carta de crédito de Salles. De fato, em termos absolutos, era uma quantia expressiva. Ainda assim, a opção de não doar o valor integralmente pode ser vista como uma estratégia.

A proposta, então, foi que se formasse uma coalizão de empresários em torno da Seleção. 0 desejo de criar o comitê adviria da preocupação de encontrar uma forma de minimizar perdas e ampliar eventuais ganhos de marketing em caso de vitória. A mobilização do empresariado era, ela própria, um modo de ampliar os possíveis ganhos políticos/simbólicos, o que aumentaria a visibilidade da campanha. Nesse processo, o que era uma ação de mecenato individual se transformou numa mobilização coletiva da classe empresarial.

Depois de anuir, Havelange teria feito um pedido especial: o de que Salles emprestasse seu nome à presidência da campanha. Em carta enviada em março de 1969, Havelange explicita os motivos para que Salles liderasse a coalizão. Seria uma forma de prestigiar à campanha. Com a liderança do embaixador, era mais fácil atrair outros indivíduos para a campanha. Seu nome funcionaria como uma espécie de fiador, garantindo o crédito de confiança necessário. Além da entrevista de Cunha, há uma carta endereçada a Salles na qual Havelange explica seu desejo e as motivações desse pedido:

Senhor Embaixador,

À medida que se aproxima a data fixada para a realização da Copa do Mundo de 1970, no México, e, antes de tal acontecimento, o compromisso que o futebol brasileiro terá que saldar frente às representações da Colômbia, Venezuela e Paraguai, cujos resultados determinarão a participação ou a ausência do Brasil naquela competição, aumentam as responsabilidades da CBD perante o povo brasileiro. 
OS EMPRESÁRIOS, A PÁTRIA E A BOLA: NACIONALISMO, ORGANIZAÇÃO EMPRESARIAL E O FINANCIAMENTO DA SELEÇÃO BRASILEIRA DE FUTEBOL DE 1970

Tais são as preocupações e como inúmeros e elevados são os compromissos resultantes desse evento futebolístico, que o desejo de colaborar manifestado por organizações do gabarito da UBB, ou por cidadãos da envergadura e da importância de V. Ex. ${ }^{a}$ na vida política, social e econômica financeira do país, representa a esperança ou quase a certeza de que as dificuldades serão superadas.

A visita feita a esta entidade pelo Sr. Pedro McGregor, Assistente da Diretoria da UBB quando, perante a nossa diretoria, expôs, em linhas gerais, um plano de apoio financeiro à CBD com vistas à Copa do Mundo, trouxe-nos a certeza de que as esferas mais importantes do país avaliam o significado do futebol como veículo de propaganda de uma nação, como reconhecem o quanto o povo brasileiro deseja a conquista do título mundial em 1970.

A Diretoria da CBD, absolutamente confiante no decisivo apoio de V. Ex. ${ }^{a}$, resolveu criar o Comitê Brasileiro da Seleção de 70 (COBRAS), e envia por meio deste, um veemente apelo no sentido de que V.Ex. ${ }^{a}$ assuma a direção da campanha.

A presença de V.Ex. à à frente de tal movimento é a maior e melhor garantia de que o sucesso nos aguarda. Ao lado de V.Ex. ${ }^{a}$. estarão todos aqueles que, tendo algo para dar, não hesitarão em fazê-lo, tal a qualidade e a capacidade do timoneiro da campanha.

Resolveu ainda a Diretoria solicitar de V.Ex. ${ }^{a}$ a elaboração do plano cujas bases nos foram apresentadas pelo Pedro McGregor, colocando desde já os seus serviços à disposição de V.Ex. ${ }^{a}$ para qualquer informação.

$\mathrm{Na}$ expectativa de um breve pronunciamento, apresentamos a V.Ex. ${ }^{a}$ Senhor Embaixador os nossos protestos de grande respeito e elevada estima.

Havelange. $^{7}$

Dois meses após a troca inicial de correspondência, o primeiro jantar dos empresários tornou pública a campanha para angariar fundos para a Seleção. Aberto com um desfile de misses estaduais, a solenidade contou com a participação de jornalistas, empresários, do general Siseno Sarmento, além dos jogadores da seleção, as "Feras do Saldanha". Os nomes dos pratos homenageavam os personagens principais daquele encontro: como entrada, creme de aspargos à Havelange; de prato principal, bife à João Saldanha; e, no fim, um café à Pelé.

Cerca de 100 mil cruzeiros novos (ou 25 mil dólares) foram doados para a preparação da Seleção da CBD somente naquela noite - cerca de 10 por cento do valor total que os empresários pretendiam arrecadar. ${ }^{8}$ Um dos jornalistas presentes no encontro era Nelson Rodrigues. Sem exagero, pode-se dizer que o cronista tricolor se tornou uma espécie de porta-voz não oficial da campanha. Escrita logo após o primeiro encontro, a crônica abaixo seria a primeira de uma série de textos produzidos e dedicados à Campanha do Empresariado Pró-Seleção de 1970: 
Não deixa de ser romântico o apoio que os nossos empresários estão dando ao scratch brasileiro. O exemplo de Walther Moreira Salles define um novo Brasil. No passado, o homem rico não saberia dizer se a bola é redonda ou quadrada. E vejam como Walther Moreira Salles recebeu, de braços abertos, o apelo que lhe fez Havelange. Está trabalhando para a seleção. Vivo eu a dizer que o scratch é a pátria de chuteiras. Pois os nossos empresários pensam assim, sentem assim, veem assim (Rodrigues, 1969).

A propaganda era clara: se, no passado, havia um gap entre a agência do empresariado e os sentimentos populares, no Brasil de 1969 os empresários viviam e sentiam os problemas da nação como se fossem os seus próprios. Não havia conflito entre as classes subalternas e as dominantes, de modo que ambas viviam e sentiam os problemas de um só Brasil. 0 discurso dos anseios da pátria em comunhão ia ao encontro da narrativa do discurso oficial do regime político. Essa narrativa, sem dúvida, foi vulgarizada pelos órgãos institucionais de propaganda, em particular pela Assessoria Especial de Relações Públicas (Aerp), mas permeou atores da sociedade civil. Em "À sombra das chuteiras imortais", uma de suas crônicas escritas na sua coluna do jornal 0 Globo, Nelson vocalizava, exagerava e reproduzia o discurso oficial:

Faço esta introdução para chegar a Walther Moreira Salles. [...] Ora, entendo que uma das mais sérias conquistas do futebol brasileiro foi a de Walther Moreira Salles. Eis aí uma admirável figura de brasileiro. [...] o time nacional, sendo o melhor do mundo, é também o mais pobre. [...]. Ninguém ignora que os nossos clubes vergam ao peso das dívidas como uma árvore ao peso dos frutos. E se é assim por que deixar o homem rico como um marginal dos grandes acontecimentos esportivos? Walther Salles é sensível para com as coisas brasileiras. Ele sentiu o que representa o scratch para o povo e para o Brasil. [...] Walther Salles convocou os empresários. Transmitiu-Ihes seu entusiasmo. Essa mobilização significou tanto, tanto. Imaginem a situação do scratch. Com algum exagero, eu diria que se os jogadores ficassem doentes teriam que se internar numa enfermaria de indigentes da Santa Casa. Hoje eu ousaria dizer que o scratch está menos pobre. [...] 0 povo sente que este scratch vai ser campeão. Agora vemos os empresários trabalhando pela seleção. Nunca houve isso. Os lorpas, os pascácios, os bovinos advertem contra o otimismo. Deviam fazê-lo inversamente contra o pessimismo. Mas é fácil perceber que o otimismo está em toda a parte: difuso, volatilizado, atmosférico. Sim, nós respiramos otimismo (1969).

Escrita dois meses após a primeira, a crônica contém muitos elementos narrativos interessantes, como a celebração do otimismo, da comunhão produzida pelo nacionalismo, e a centralidade da figura de Salles como empresário desse "novo tempo". Na arena pública, Salles era uma espécie de símbolo capaz de condensar a atuação e as representações positivas sobre esse grupo político.

Neste trabalho pedagógico, o objetivo era parecer "sensível às coisas brasileiras" e se aproximar das classes subalternas. A diluição do conflito de classes e de raças em torno de uma ideia 
comum de Brasil era o que dava a tônica do discurso propagandístico. Salles e os empresários brasileiros não seriam mais alheios aos "grandes acontecimentos do povo", para retomar a imagem de Nelson Rodrigues. Dessa vez, eles tomariam a dianteira para construir uma nação moderna.

O leitor de época não teria dificuldade para identificar esse "novo tempo" com o governo Médici, que prometia um Brasil desenvolvido e pujante do ponto de vista econômico. Mais do que isso, evocar a pobreza da Seleção era a estratégia do cronista para apresentar os empresários como os responsáveis por redimir a Seleção/nação brasileira. Essa versão, entretanto, não poderia ser mais enganosa. Se os empresários brasileiros se interessavam pela Seleção, era por sua força política, econômica e simbólica, e não por sua fraqueza institucional. Não havia nada de romântico nem de salvacionista nesse mecenato. Tratava-se de uma estratégia de marketing, com objetivos, metas e um programa de execução bem delimitados. Investindo no futebol, os empresários enxergaram uma chance de se projetar na arena pública, com uma agenda própria de instrumentalização esportiva.

\section{O EMPRESÁRIO COMO REPRESENTANTE DO POVO}

P or sua dimensão fluida, o futebol é um espaço discursivo para a disputa de visões de mundo na sociedade civil (Guedes, 1977). 0 desenho das premissas da campanha não deixa dúvidas desse objetivo mais amplo de conquistar a opinião pública, inserindo no futebol representações e visões de mundo previamente construídas. Não cabe aqui entrar no debate sobre a forma como essas mensagens foram recebidas pelo conjunto da população. Basta dizer que os documentos encontrados mostram como esses grupos pretendiam se apropriar do futebol e da Seleção para construir representações positivas sobre si mesmos.

Em maio de 1969, um documento interno era formulado por Giulite Coutinho, futuro presidente da Confederação Brasileira de Futebol (CBF) e importante empresário do ramo do café, e Rafael de Almeida Magalhães, ex-secretário de esportes da cidade do Rio de Janeiro na gestão de Carlos Lacerda e amigo pessoal de Havelange. 0 documento estimava que os empresários seriam capazes de acumular cerca de 1 milhão de cruzeiros novos, valor, inclusive, maior do que o que fora requisitado pelos dirigentes da CBD. Em caso de excedente, este seria repassado à $\mathrm{CBD}$ e destinado aos esportes amadores.

Assinado a quatro mãos, o documento indicava as premissas, os objetivos gerais e 0 objetivo específico:

I. Premissas:

a. Assumir a iniciativa privada o encargo de liderar amplo movimento comunitário visando à obtenção de recursos suficientes para assegurar a presença do futebol brasileiro na Copa do Mundo de 1970; 
b. Demonstrar capacidade de organização e mobilização da iniciativa privada como requisito para suscitar uma consciência de participação efetiva da comunidade na consecução de um projeto comum;

c. Dar prova da eficiência da iniciativa privada e da capacidade potencial da comunidade em participar de projetos comuns, cujos dimensão e alcance superam os interesses imediatos de cada integrante;

\section{d. Comprovar que a iniciativa privada é sensível a uma atividade popular;}

e. Demonstrar que é possível despertar um sentimento de participação numa comunidade desde que procure motivá-la adequadamente;

f. Reconhecer que as competições esportivas internacionais revestem-se de incontestável valor social e cívico, além dos seus aspectos promocionais irrecusáveis;

g. Tornar supletivo o eventual auxílio dos poderes públicos;

h. Associar a comunidade, através da sua participação ativa, na conquista da Copa do Mundo, fazendo de cada qual colaborador eficiente no êxito da empreitada comum.

II. Objetivos gerais:

- Organizar a iniciativa privada como condição para organizar a participação coletiva;

- Solicitar pequenas contribuiç̧ões de todos, mediante campanha motivacional, com recursos a incentivos artificiais;

- Promover a solidariedade da comunidade pela mobilização ampla e generalizada da iniciativa privada. (grifos nossos) ${ }^{9}$

"Participação coletiva", "solidariedade", "mobilização cívica", "empreitada comum" - essas são expressões que ilustram como o objetivo da campanha era dar concretude ao sentimento de nacionalidade. Além desse aspecto, a intenção era aproximar o empresário do homem comum, num trabalho pedagógico de valorização da iniciativa privada. Para tanto, a mobilização da sociedade civil era fundamental. Algo implícito era a crítica à visão do Estado como o único preocupado com os grupos desfavorecidos (premissa g). Assim, há uma série de menções à necessidade de "tornar supletivo" — isto é, dispensável — o poder público, algo que valorizaria a iniciativa privada. Esta era uma crítica política comum feita pelos empresários mesmo na década de 1970: eles se ressentiam da hegemonia de uma visão estatista da economia. A intenção era mostrar como a iniciativa privada publicamente preocupada com a Seleção poderia tornar a opinião pública mais sensível à atividade empresarial.

Dessa forma, a premissa $h$ do documento acima era a que melhor revelava as aspirações gerais da campanha: "associar a comunidade [empresarial] [...] à conquista da Copa do Mundo". Distribuído nas agências, o panfleto da campanha deixava isso muito claro, ressaltando a participação do empresariado como concorrente ao governo: "Até hoje apenas o governo e a 
OS EMPRESÁRIOS, A PÁTRIA E A BOLA: NACIONALISMO, ORGANIZAÇÃO EMPRESARIAL E O FINANCIAMENTO DA SELEÇÃO BRASILEIRA DE FUTEBOL DE 1970

CBD se preocupavam com os problemas da seleção nacional de futebol." Sob esse último aspecto, as possibilidades de êxito e rentabilização de lucros simbólicos eram bastante elevadas. Um panfleto distribuído nas agências da UBB explicitava:

Até quatro anos atrás, isto é, até a última Copa do Mundo, apenas o Governo e a Confederação Brasileira de Desportos preocupavam-se com os problemas da Seleção Nacional de Futebol. Entendemos que a participação de nosso país na Copa do Mundo não deve e não pode acontecer à nossa revelia. $O$ futebol hoje em dia faz parte da vida sociológica das nações e dos povos. E os empresários do Brasil sentem o dever de dar sua contribuição à presença do Brasil na disputa do campeonato mundial de futebol, que se constitui, sem dúvida, um dos fatos mais importantes da vida do país. Com este propósito, conscientes de que como empresários não podemos ficar alheios à vida nacional, aceitamos a liderança de uma campanha que objetiva proporcionar aos nossos jogadores as condições necessárias e materiais para que nesta disputa internacional, representem o Brasil em condições de elevá-lo à altura em que todos queremos e o país merece. ${ }^{10}$

Para alcançar o êxito, era preciso vencer a Copa do Mundo. Por essa razão, o dinheiro arrecadado pelo empresariado seria destinado a uma preparação de tipo científica, certo de que isso Ihes garantiria as condições da conquista em 1970. Esse plano ficou conhecido como "Planejamento México". A crença na capacidade científica dos métodos da educação física foi fundamental para que eles liberassem boa parte dos recursos. A entrevista com Cunha revela um conhecimento dos personagens, bem como do nome das técnicas e dos métodos de preparação física desenvolvido por Raoul Mollet, Kenneth Cooper e pelo Conselho Internacional de Esportes Militares (Cism), prova de que o empresariado também se assuntou da cooperação técnica. ${ }^{11}$

Numa das reuniões junto aos empresários, o general Sarmento salientou à imprensa que a estrutura do Exército estaria à disposição da Seleção — era a tal aliança entre empresários e militares de que falava Cunha. Enquanto os primeiros entrariam com as verbas necessárias para o custeio do investimento em ciência e da preparação da seleção, o Exército disponibilizaria o know-how, o capital humano e os espaços físicos. ${ }^{12}$

Os empresários decidiram montar uma estrutura nacional, segmentada em comitês estaduais. As cinco principais metrópoles do país (Rio de Janeiro, São Paulo, Recife, Belo Horizonte e Porto Alegre) contariam com um comitê de empresários, cada qual liderado por um representante proeminente. No caso de Recife e Belo Horizonte, não foi possível descobrir quem presidiu o comitê. Nas outras, a lógica regional era semelhante à da presidência nacional ocupada por Salles. Cada empresário emprestaria seu prestígio ao comitê, de forma que outros da comunidade o seguiriam. 
Em São Paulo, Salles convidou Paulo Salim Maluf, mas, após este declinar, foi o industrialista José Ermírio de Moraes, do Grupo Votorantim, quem levou o projeto adiante (Paulo..., 1969). Em Porto Alegre, o prefeito Thompson Flores, engenheiro civil e empreiteiro do setor elétrico, assumiu a responsabilidade. Em 1970, Salles escreveu carta do próprio punho solicitando doações a um grupo seleto de amigos:

Como é de seu conhecimento, o Empresariado Brasileiro está colaborando numa Campanha Financeira destinada a obter recursos que possam, pelo menos em parte, cobrir as vultuosas despesas necessárias à preparação do selecionado brasileiro de futebol que irá se apresentar na Copa do Mundo.

Aceitei a presidência desta Campanha incentivado e apoiado por inúmeros empresários amigos, convictos que não podemos ficar alheios a um acontecimento tão importante na vida da Nação.

Certo de contar com a sua valiosa colaboração, estou enviando estojo contendo uma das medalhas de ouro, cunhada pela casa da Moeda e com as quais estamos obtendo os fundos necessários à campanha.

Qualquer contribuição acima do valor intrínseco da moeda cunhada, que é de cerca de 2 mil cruzeiros novos, será muito apreciada por este comitê.

Fique certo de que o Desporto Nacional Ihe ficará imensamente grato por este generoso gesto.

Walther Salles ${ }^{13}$

Os documentos depositados no arquivo se concentram no Comitê Carioca, chefiado por Antônio Galloti, do Grupo Light. O comitê era, inclusive, subdividido em seis setores, definidos pela atividade produtiva: Indústria, Comércio, Clubes, Finanças, Publicidade e Imprensa, além de um setor geral de Coordenação. Interessante ver que, na lista dos membros da campanha, aparecem empresários vencedores e que concederam o Prêmio Mascate para Havelange em 1970, como Jessé Pinto Silveira, da CNC, e Jorge Paulo Geyer, da Associação de Comerciantes Varejistas do Rio de Janeiro.

Empresários conhecidos também estavam na lista, como Carlos Alberto Vieira, presidente do Banco do Estado da Guanabara; Oscar Bloch, da Manchete; João Calmon, dos Diários Associados e da Revista Cruzeiro; e Guilherme da Silveira Filho, da Fábrica Bangu. ${ }^{14}$

A lista de doadores da campanha era extensa. Havia empresas como Gillette, Grupo Light, a siderúrgica Belgo-Mineira, a cervejaria Skol, o Banco Boavista, o Banco do Estado da Guanabara e o BIB. Doações individuais como a de Marcos Carneiro de Mendonça, ex-goleiro do Fluminense e presidente da Belgo-Mineira; Amador Aguiar, do Bradesco; o próprio João Havelange e Ney Carvalho também se destacam — cada um comprou cerca de 50 moedas. 
Essa diversidade ilustra como os empresários foram capazes de mobilizar amplos setores, ainda que se possa falar numa predominância de agentes ligados ao setor financeiro. ${ }^{15}$

A campanha foi baseada em doações, feitas da seguinte forma: quem quisesse contribuir, compraria moedas de ouro da Seleção brasileira cunhadas sem custos pelo governo na Casa da Moeda. Cada moeda teria um valor intrínseco de 2 mil cruzeiros (50 dólares). Qualquer valor acima dessa base inicial seria diretamente doado à Seleção. Com a compra da moeda, 0 empresário poderia fazer a doação e, em seguida, recuperar o valor parcialmente, revendendo as moedas no próprio estabelecimento comercial. Caso não as vendesse, assumia para si o prejuízo integral, e a compra podia ser encarada como uma doação.

Além de comprar ouro, a população de menor renda poderia comprar diplomas intitulados "Amigos da Seleção". Foram 25 mil diplomas impressos, que custavam 500 cruzeiros novos (12 dólares) e 200 cruzeiros novos (5 dólares) cada. Havia itens de valor ainda menor, como adesivos, mas que não aparecem na contabilidade da campanha. Nessa linha, o interessante é notar que estes de maior valor (diplomas e moedas) foram vendidos nas agências da UBB espalhadas Brasil afora, que se valeu dessa estrutura para comercializar os ativos. As recomendações internas mostram Cunha solicitando que os gerentes das agências bancárias oferecessem os produtos para os clientes tradicionais do banco. Abaixo, o press release da campanha, distribuído nos jornais de grande circulação do período, dá alguns detalhes de como seriam feitas as vendas:

Press release. Futebol mexe com todos. É o esporte do Brasil, capaz de nos dar as maiores alegrias. E a seleção brasileira, que vai ao México buscar o tri, precisa de você. 0 comitê financeiro, liderado pelo Embaixador Walther Moreira Salles, presidente da UBB, pôs à venda moedas de ouro, especialmente cunhadas pela Casa da Moeda, que estão em exposição na agência Patriarca e vendidas por dois mil cruzeiros novos. Além das moedas, o torcedor brasileiro pode adquirir em qualquer agência o diploma Amigo da Seleção, que corresponde a sua contribuição financeira no valor de 500 e 200 cruzeiros novos. Colabore. ${ }^{16}$

Na peça publicitária, ajudar a seleção economicamente se apresentava como um dever cívico do brasileiro. Lado a lado com a UBB, a companhia de gás Shell foi uma das primeiras a se manifestar publicamente e a se engajar na campanha. A equipe de marketing da Shell criou o slogan da campanha - "Pra frente, com as feras" - e desenhou quase todo o material de divulgação. A empresa foi elogiada tanto no discurso de abertura, por Salles, quanto no de encerramento da campanha, por Cunha. 0 marketing da Shell foi o responsável por tornar a campanha pública, colocando anúncios nos principais semanários da época. 
A presença do slogan criado por Saldanha na peça publicitária indica a centralidade do técnico para a campanha de marketing promovida pelos empresários. Saldanha era o garoto-propaganda ideal. Para o comando da CBD, ele podia funcionar, a um só tempo, como o rosto da Seleção, a vitrine da campanha e uma espécie de escudo de proteção para Havelange. Saldanha, entretanto, ao contrário do que se esperava, foi demitido às vésperas da Copa do Mundo e não comandou a equipe no México. Sua saída principiou uma crise política entre os setores do empresariado, que ameaçaram interromper a campanha. Não cabe aqui discutir, porém, as supostas causas que levaram à demissão. Para as finalidades deste trabalho, basta dizer que ela foi sentida pelos empresários à frente da campanha. Rememorando a história, Cunha classificou o episódio de uma situação "preocupante para o Havelange, preocupante para os empresários que lá estavam também". ${ }^{17}$

A primeira razão de preocupação era que a saída de Saldanha pudesse abalar a equipe do ponto de vista técnico. Como ressaltado, a aflição com o resultado é inerente a qualquer ação de marketing no futebol. Na carta de encerramento, o próprio Cunha escreveu que "não foi fácil, pois muitos em determinada fase se desinteressaram pela campanha, temendo o insucesso do nosso selecionado que, felizmente, graças à técnica, à organização, à disciplina e à determinação de seus integrantes soube superar as crises pelas quais passou." A apreensão era para saber de que forma a substituição de Saldanha se daria e se isso poderia, eventualmente, abalar a equipe. ${ }^{18}$

Para além do aspecto técnico, havia uma dimensão financeira. Logo depois da saída de Saldanha, foi o próprio Galloti, na condição de presidente do Comitê Carioca e vice-presidente nacional, quem the fez um pedido especial. Ele queria manter o nome de Saldanha nos diplomas que seriam vendidos nas agências da UBB. Os diplomas já haviam sido impressos e, caso Saldanha não aceitasse, precisariam ser reimpressos. As atas das reuniões dos empresários mostram a preocupação e a necessidade de economizar o tempo e o dinheiro da reimpressão. Na carta, lê-se:

\section{Meu caro João Saldanha,}

Conforme é do conhecimento de V.S. ${ }^{a}$, o Comitê Carioca Pró-Seleção, incumbido de arrecadar recursos, tomou a decisão, entre outras, de imprimir dezenas de milhares de diplomas, para serem colocados em todo o país. Os diplomas se acham impressos e neles figura, como nome eminente, o de João Saldanha, técnico da seleção.

Embora não seja mais o técnico, V.S ${ }^{a}$. foi um dos inspiradores dos trabalhos em que se empenhou e se empenha o Comitê Carioca e o Comitê Nacional Pró-Seleção. 
OS EMPRESÁRIOS, A PÁTRIA E A BOLA: NACIONALISMO, ORGANIZAÇÃO EMPRESARIAL E O FINANCIAMENTO DA SELEÇÃO BRASILEIRA DE FUTEBOL DE 1970

Na fase dos jogos eliminatórios, sua notável capacidade técnica e dedicação à frente do selecionado brasileiro fizeram com que as nossas cores, vitória após vitória, conquistassem brilhantemente o direito de ir ao México. Por isso, o seu nome no diploma é imperativo.

Não é impossível nem difícil fazer novas impressões, mas o diploma desrespeitaria os fatos se o nome de V.S. ${ }^{a}$ nele deixasse de constar ao lado dos nossos magníficos atletas e do técnico Mario Lobo Zagallo.

O objetivo desta carta, que the entrego em mãos, é solicitar que, pela concordância na cópia da mesma, fique o Comitê Carioca autorizado a lançar os diplomas com a assinatura do técnico que encheu de orgulho os brasileiros, no comando da equipe nacional, ao superar todos os obstáculos e equipes que enfrentamos na fase das eliminatórias.

Agradeço, pelo Comitê Carioca Pró-Seleção, a acolhida, que dispensa à presente, e me subscrevo seu admirador de sempre.

Antônio Galloti19

A importância do episódio foi tal que a carta não chegou a ser enviada pelos Correios, e sim entregue em mãos por Galloti. Embora seja menos conhecido para o leitor contemporâneo do que Salles, a reputação de Galloti nos meios empresariais era tão alta quanto. Das mãos do senador Jessé Pinto Freire, ele receberia, em 1973, assim como Havelange fizera em 1970, o Prêmio Mascate do Ano. Também foi considerado o "executivo do ano" pela revista Visão. No âmbito internacional, fazia parte de um seleto conselho internacional do Chase Manhattan Bank, ao lado de figuras conhecidas pela burguesia transnacional, como Giovanni Agnelli, presidente da Fiat, e Hermann Abbs, do Deutsche Bank.

Por outro lado, se a ligação de Salles com o regime ditatorial pode ser caracterizada como pragmática, a adesão ideológica de Galloti ao regime ditatorial era conhecida. Galloti era um dos líderes e financiadores do Instituto de Pesquisas e Estudos Sociais (Ipes), tendo participando ativamente das reuniões do grupo e da arquitetura do golpe de 1964. ${ }^{20}$

Em 1970, Galloti e os demais empresários pensavam que o nome de Saldanha pudesse funcionar como atrativo para a venda dos diplomas da Seleção, de modo que não hesitaram em Ihe escrever para que o nome ali permanecesse. Para Galloti e os outros empresários, o que estava em jogo era uma estratégia de marketing, e o nome de Saldanha tinha valor comercial. Assim, é importante observar que as divergências ideológicas não aparecem como uma questão na documentação - tanto é que Galloti, justamente o empresário mais alinhado com o regime político, foi quem entregou a carta a Saldanha. 


\section{CONCLUSÃO - A DISPUTA EM TORNO DA CHEFIA DA DELEGAÇÃO}

ntes do embarque para o México, o último ato da campanha foi o convite de Havelange
para Salles chefiar a delegação. A recusa, escrita em carta para Havelange, chegou a circular nos principais jornais da época:

Prezadíssimo amigo João Havelange,

Recebi, com emoção, o seu convite para chefiar a delegação brasileira de futebol à Copa do Mundo de 1970. Em minha infelizmente não muito curta vida de homem público poucas vezes tanto me tocou a oferta de cargo tão desinteressado e encerrando tamanho apelo aos impulsos de dedicação de que todos nós somos capazes em maior ou menor escala. Venho colaborando, modesta, mas ativamente, como você sabe, nos esforços financeiros indispensáveis a que 0 Brasil possa representar-se certamente à altura de suas tradições. Aliar a isto a presença direta na disputa, e ainda mais, a liderança efetiva da seleção, é apaixonante.

Não obstante, não posso aceitar o convite. Creio que, embora meus inúmeros afazeres, sempre acharia um meio de ausentar-me o tempo necessário. Mas o que me falta, e a você permito dizê-lo, pois tenho a certeza de que não suporá que eu esteja em busca de cumprimentos, é a capacidade específica de assumir tal chefia. Mero aficionado, conquanto vibrante, das cores nacionais, eu seria muito provavelmente um mau dirigente que não saberia dar lhes em tempo a melhor solução. Em vez de servir à seleção, eu a prejudicaria, e não quero carregar comigo semelhante remorso. É por isso que, agradecendo, de todo coração, aquele convite, peço que encarecidamente que me dispense deles, e que me permita, como é direito e desejo de todos nós, a liberdade integral de torcedor, cuja única meta é a vitória em si. Nada mais. [...] Rio de Janeiro, 4 de março de 1970.21

Havelange ainda convidou Salles para se tornar "delegado de honra", uma função meramente formal e honorária. ${ }^{22}$ Dessa vez, porém, Salles não respondeu por escrito. Na carta acima, é visível a preocupação que sua reputação pudesse sair abalada pela derrota. De todo jeito, o fim da história é conhecido pela literatura. Depois da recusa de Salles, Havelange convida o brigadeiro Jerônimo Bastos, presidente do Conselho Nacional dos Desportos, para chefiar a delegação. Não obstante, é interessante notar que o Brigadeiro não foi a primeira escolha.

0 vínculo entre Havelange e os empresários, representado por Salles, era tão ou mais forte do que aquele construído entre a CBD e o núcleo burocrático do Estado brasileiro. A recusa de Salles em ocupar um cargo na instituição ajudaria a tornar o apoio do empresariado um episódio invisível na memória social. Na época, a vitória do Brasil fez com que esses grupos lucrassem tanto simbólica quanto politicamente junto à sociedade civil. Salles pode se projetar "junto ao povo", algo que certamente ajudaria no processo de expansão e consolidação do seu banco. 
Na historiografia política sobre o futebol brasileiro, poucos assuntos são tão estudados quanto a vitória do Brasil na Copa do Mundo em 1970. Tradicionalmente, ela tem sido contada como uma fábula de apropriação política pelos militares. Representados pelo então presidente Médici, os militares teriam utilizado a seleção como forma de garantir e manter as posições de autoridade, fomentando o discurso nacionalista do período.

Em linhas gerais, o debate gira em torno de qual a extensão, a natureza e o impacto desse discurso no conjunto da sociedade civil. Um conjunto de autores argumenta que, embora houvesse a intenção dos agentes em domesticar as massas pelo futebol, a recepção das mensagens sobre a Seleção de 1970 teria sido heteróclita (Florenzano, 2009). Outros historiadores argumentam que o claro uso político dos militares da Seleção teve impactos diretos na construção de uma hegemonia política (Magalhães, 2014).

Parece, todavia, haver consenso de que o êxito do selecionado brasileiro de 1970 teria sido capitaneado e capitalizado exclusivamente pelos militares. Seriam eles os responsáveis por ampliar a euforia nacionalista provocada pelo milagre econômico com o triunfo da equipe de Mario Jorge Lobo Zagallo. Este artigo, de certa forma, diverge e amplia essa linha interpretativa. Ainda que pareça claro que os militares atuaram nessa direção, eles não fizeram voo solo. Nessa empreitada, estiveram a seu lado amplos setores do empresariado. Egressos de diversos setores da economia, em particular do capital financeiro, eles ajudaram a financiar o planejamento para a Copa do Mundo do México. Tais grupos tinham, à sua própria maneira, uma agenda de instrumentalização política do futebol e, não raro, estiveram lado a lado com os militares.

Por fim, vale a pena refletir sobre os motivos pelos quais essa parceria entre o empresariado e a CBD não consta dos livros de história de caráter acadêmico e na memória nacional. Pode-se começar ressaltando o fato óbvio de que os Arquivos Walther Moreira Salles permanecem fechados ao público acadêmico. Essas reuniões entre Havelange e os empresários foram fartamente documentadas pela grande imprensa do período, fonte mais do que conhecida pela literatura. Salles chegou a publicar sua carta recusando o convite de chefiar a delegação em jornais de grande circulação, e os acadêmicos que se debruçaram sobre a Copa do Mundo de 1970 preferiram deixar essa história à margem de suas teses. ${ }^{23}$

Nesse quesito, deve-se concordar com o historiador Daniel Aarão Reis Filho, que pontua que, ao curso do processo de abertura política, houve uma espécie de "expurgo da ditadura pela sociedade" (2000: 8), vista como algo essencialmente negativo e associada exclusivamente ao grupo militar. Nessa linha, "hoje quase ninguém quer se identificar com a ditadura [...] Com isso, atitudes que tendem a estabelecer uma ruptura drástica entre o passado e o presente se estabelecem e induzem ao esquecimento e ao silêncio de um processo" (2000: 16). 
Em 2019, as palavras de Reis já não soam tão atuais. Não obstante, a historiografia silencia sobre grupos e agentes que colaboraram, lucraram e atuaram de mãos dadas com 0 governo. Fundamental na construção de um clima de euforia em 1970, a vitória na Copa do Mundo e seus usos políticos deveriam ser associados à figura do presidente Médici - a face, por definição, do regime autoritário. A colaboração do empresariado na campanha e seus eventuais ganhos econômicos, políticos ou simbólicos pareciam não ter lugar nessa narrativa.

\section{NOTAS}

1 Os valores estão disponíveis em Coaracy (1978: 69) e também no relatório anual da CBD (1970). Atualizado, o valor é, evidentemente, uma aproximação, feita com base no site https://www.fee.rs.gov.br/servicos/ atualizacao-valores/. A tabela disponível pela Fundação de Economia e Estatística do Rio Grande do Sul toma por base o Índice Geral de Preços (IGP-FGV).

2 Entrevista cedida por Bellini Cunha ao autor. Rio de janeiro, ago. 2016.

3 Entrevista cedida por Bellini Cunha ao autor. Rio de janeiro, ago. 2016.

4 Entrevista cedida por Bellini Cunha ao autor. Rio de janeiro, ago. 2016.

5 A maior parte das informações sobre a vida de Walther Salles foi retirada do verbete do DHBB, escrito por Mayer (1984), além de Brandão (2019).

6 De acordo com relatório da CBD (1970), as despesas totais da seleção em 1970 foram de 73 milhões de reais. 0 resto do custo foi bancado com renda de amistosos nacionais, internacionais, eliminatórias e outras verbas da instituição.

7 Carta convite (ofício número 254). Havelange convida Walther Salles. Rio de janeiro, 14 mar. 1969. Pasta 4. Campanha Nacional Pró-Seleção Brasileira, WMS. 1979. 03-14. Correspondências. Arquivo Walther Moreira Salles/Acervo IMS.

8 A notícia da participação de Siseno Sarmento está em Empresário... (1969). Notícias mais gerais podem ser encontradas em Jantar... (1969) e Banqueiro... (1970).

9 Esquema geral de trabalho, disposto em atas da reunião do Comitê Carioca em 14 de maio de 1969. WMS. PUB. Camp/Campanha Nacional Pró-Seleção Brasileira. Atas e estatutos. Arquivo Walther Moreira Salles/Acervo IMS.

10 Panfleto distribuído nas agências. WMS. 1970. 08.00 PUB. Campanha Copa 1-10. Campanha Nacional Pró-Seleção Brasileira. Arquivo Walther Moreira Salles/Acervo IMS.

11 A Biblioteca do Exército publicou, por exemplo, Mollet (1976), Cooper (1970) e Cooper (1972). Mollet era presidente do Comitê Olímpico belga.

12 Conferir entrevista cedida por Bellini Cunha ao autor. Rio de janeiro, ago. 2016. Em 1970, o general Siseno Sarmento declarou que "o Exército ajuda tudo que pode agradar ao povo. 0 Exército é o povo e o futebol é do povo. Um exemplo do que estamos ajudando: a nossa escola de educação física está à disposição da seleção" (CBD..., 1969). 
OS EMPRESÁRIOS, A PÁTRIA E A BOLA: NACIONALISMO, ORGANIZAÇÃO EMPRESARIAL E O FINANCIAMENTO DA SELEÇÃO BRASILEIRA DE FUTEBOL DE 1970

13 A estrutura da campanha aparece presente em discurso WMS. 1969. PUB. Camp/ Copa. DIS 1969. [Pasta número 2]. Arquivo Walther Moreira Salles/Acervo IMS.

14 Para a lista de doadores, conferir WMS. 1970.08.00 PUB Campanha Copa 1-10. Relatórios. Arquivo Walther Moreira Salles/Acervo IMS.

15 Antônio Galloti a Walther Moreira Salles. Correspondências. Pasta 4. Campanha Nacional Pró-Seleção Brasileira. WMS. 1968. 03-14. Arquivo Walther Moreira Salles/Acervo IMS. Na lista completa do Comitê Carioca, faziam parte do Setor Indústria: Guilherme de Silveira Filho, Guilherme Levy, Paulo Geyer, Thomas Pompeu de Souza Brazil Netto e Victor Boucas; do Setor Comércio: Antônio Carlos de Amaral Osório, Jessé Pinto Freire, Jorge Geyer, Ruy Gomes de Almeida e Venâncio Veloso; do Setor Finanças: Bellini Cunha, Carlos Alberto Vieira, Eduardo Magalhães Pinto e José Luiz Moreira de Souza; do Setor Clubes: Antônio de Bulhões Carvalho, Antônio Carlos de Almeida Braga, Francisco Eduardo de Paula Machado, Giulite Coutinho e Nelson Vaz Moreira; do Setor Publicidade: Chagas Freitas, Danton Jobim, João Calmon, embaixador João Dantas, Nascimento Brito e Oscar Bloch; do Setor Coordenação: Eduardo Galloti, Eduardo Bahout, José Rubem Fonseca e Rafael de Almeida Magalhães.

16 Referência, pasta 4. WMS. PUB. Camp. Copa. 1970/00.00. Arquivo Walther Moreira Salles/Acervo IMS.

17 Entrevista cedida por Bellini Cunha ao autor. Rio de Janeiro, ago. 2016.

18 Carta de encerramento escrita por Bellini Cunha, sem data. Pasta 7. Campanha Copa. WMS. PUG. Comp. Copa 70. Arquivo Walther Moreira Salles/Acervo IMS.

19 Antônio Galloti a João Saldanha, carta de 25 de março de 1970. Pasta 4. Campanhas. 1970. WMS. 1969. 03-14. Correspondências, 45 folhas. Arquivo Walther Moreira Salles/Acervo IMS.

20 Galloti é um dos personagens da tese de doutoramento de Dreifuss (1981). Vale também consultar Dias (2010).

21 Carta de Walther Salles a João Havelange. Rio de janeiro, 4 mar. 1970. Pasta 4. Campanhas. 1970. WMS. 1969. 03-14. Correspondências, 45 folhas. Arquivo Walther Moreira Salles/Acervo IMS.

22 Carta de João Havelange a Walther Salles. Rio de Janeiro, 13 mar. 1970. Pasta 4. Campanhas. 1970. WMS. 1969. 03-14. Correspondências, 45 folhas. Arquivo Walther Moreira Salles/Acervo IMS.

23 Salvo três páginas dedicadas a essa ação na dissertação de Marczal (2011).

\section{REFERÊNCIAS BIBLIOGRÁFICAS}

AS MOEDAS de ouro em prol da seleção. Diários associados, Rio de Janeiro, 30 abr. 1970.

BANQUEIRO janta com as feras. O Globo, Rio de Janeiro, 1 jan. 1970.

BRANDÃO, Rafael Vaz da Motta. Os Moreira Salles, os Setúbal e os Villela: finanças e poder no Brasil. In: CAMPOS, Pedro Henrique Pedreira; BRANDAO, Rafael Vaz da Motta. Os donos do capital: a trajetória das principais famílias empresariais do capitalismo brasileiro. Rio de Janeiro: Autografia, 2018.

CBD consegue ajuda financeira à seleção. O Estado de São Paulo, São Paulo, 1 jul. 1969.

COARACY, Vivaldo. João Havelange: determinação e coragem. Rio de Janeiro: Editora Nacional, 1978. 
CONFEDERAÇÃO BRASILEIRA DE DESPORTOS. Relatório da CBD. Rio de Janeiro: Imprensa Nacional, 1970. COOPER, Kenneth. Aptidão física em qualquer idade: o método cooper. Rio de Janeiro: Fórum - Biblioteca de Educação Física do Exército, 1970.

COOPER, Kenneth. Capacidade anaeróbica: organizado pelo preparador dos tricampeões, Claudio Coutinho. Rio de Janeiro: Fórum: Biblioteca de Educação Física do Exército, 1972.

DIAS, Sonia. Antônio Galloti. In: DIAS, Sonia. Dicionário Histórico Biográfico Brasileiro. Disponível em: http:// www.fgv.br/cpdoc/acervo/dicionarios/verbete-biografico/gallotti-antonio?fbclid=IwAR2aNY61Qh1jMPhB-v7J4VO8plhcqYLZE5C_Gipk6xAebfXZtd_67laFhMA. Acesso em: 19 fev. 2019.

DREIFUSS, René Armand. 1964: a conquista do Estado - ação política, poder e golpe de classe. Petrópolis: Vozes, 1981.

EMPRESÁRIO confia na Seleção 1970. Correio da Manhã, Rio de Janeiro, 1 jul. 1969.

FICO, Carlos. Ditadura militar brasileira: aproximações teóricas e historiográficas. Tempo e Argumento, v. 9, n. 20, p. 5-74, 2017.

FLORENZANO, José Paulo. A democracia corinthiana: práticas de liberdade no futebol brasileiro. São Paulo: Fapesp/Educ, 2009.

GUEDES, Simoni Lahud. O futebol brasileiro: Instituição Zero. Dissertação (Mestrado em Antropologia Social) - Museu Nacional. Universidade Federal do Rio de Janeiro, Rio de Janeiro, 1977.

JANTAR hoje dos amigos da seleção. Jornal dos Sports, Rio de Janeiro, 30 jun. 1969.

MACARINI, José Pedro. A política bancária do regime militar - o projeto de conglomerado (1967-1973). Economia e sociedade, v. 16, n. 3, dez. 2017.

MAGALHÃES, Lívia Gonçalves. Com a taça nas mãos: sociedade, Copa do Mundo e ditadura no Brasil e na Argentina. Rio de Janeiro: Lamparina, 2014.

MARCZAL, Ernesto Sobocinski. O caneco é nosso: futebol, política e imprensa entre 1969 e 1970. 2011. Dissertação (Mestrado em História) - Setor de Ciências Humanas, Letras e Artes, UFPR, 2011.

MARTINS FILHO, J. R. O palácio e a caserna: a dinâmica militar das crises políticas na ditadura, 1964-1969. São Carlos: EdUFSCar, 1995.

MAYER, Jorge Miguel. Walther Moreira Salles. In: Dicionário Histórico Biográfico Brasileiro. Rio de Janeiro: FGV, 1984.

MOLLET, Raoul. Pranchas de treinamento esportivo. Rio de Janeiro: Fórum - Biblioteca de Educação Física do Exército, 1976.

PAULO Maluf será o convidado por Walther Salles para presidir o Comitê Paulista de ajuda a seleção brasileira. Diário da Noite, Rio de Janeiro, 4 jul. 1969.

REIS FILHO, Daniel Aarão. Ditadura militar, esquerdas e sociedade. São Paulo: Zahar, 2000.

RODRIGUES, Nelson. À sombra das chuteiras imortais. O Globo, Rio de Janeiro, 25 mar. 1969.

SOARES, Antonio Jorge Gonçalves; SALVADOR, Marco Antonio Santoro; BARTHOLO, Tiago Lisboa. 0 "futebol arte" e o "planejamento México" na copa de 70: as memórias de Lamartine Pereira da Costa. Movimento (Esefid/UFRGS), v. 10, n. 3, p. 113-130, 2004. 